\title{
Mangosteen Concentrate Drink Supplementation Promotes Antioxidant Status and Lactate Clearance in Rats after Exercise
}

\author{
Ching-Chien Chang ${ }^{1,2}$, Chia-Wen Chen ${ }^{1}$, Eddy Owaga ${ }^{3}$, Wan-Ting Lee ${ }^{1}$, Ting-Ni Liu ${ }^{1}$ and \\ Rong-Hong Hsieh ${ }^{1, *}$ \\ 1 School of Nutrition and Health Sciences, College of Nutrition, Taipei Medical University, Taipei 11031, \\ Taiwan; ccchang@tpcu.edu.tw (C.-C.C.); d301091008@tmu.edu.tw (C.-W.C.); mariessly@gmail.com (W.-T.L.); \\ hungchao8016@gmail.com (T.-N.L.) \\ 2 Department of Leisure and Recreation Management, College of Human Ecology, Taipei City University of \\ Science and Technology, Taipei 11202, Taiwan \\ 3 Institute of Food Bioresources Technology, Dedan Kimathi University of Technology, Nyeri 10100, Kenya; \\ eddy.owaga@dkut.ac.ke \\ * Correspondence: hsiehrh@tmu.edu.tw; Tel.: +886-2-27361661 (ext. 6557); Fax: +886-2-27373112
}

Received: 15 April 2020; Accepted: 14 May 2020; Published: 17 May 2020

\begin{abstract}
High-strength or long-duration exercise can lead to significant fatigue, oxidative stress, and muscle damage. The purpose of this study was to examine the effect of mangosteen concentrate drink (MCD) supplementation on antioxidant capacity and lactate clearance in rats after running exercise. Forty rats were divided into five groups: N, non-treatment; C, control; or supplemented with MCD, including M1, M5, and M10 (0.9, 4.5, and $9 \mathrm{~mL} /$ day) for 6 weeks. The rats were subjected to 30 min running and exhaustive-running tests using a treadmill. The blood lactate; triglyceride; cholesterol and glucose levels; hepatic and muscular malonaldehyde (MDA) levels; and antioxidant enzymes, including superoxide dismutase (SOD), glutathione peroxidase (GPx), and catalase (CAT), were analyzed. The results of this study demonstrated that MCD supplementation can increase GPx and CAT activities, alleviate oxidative stress in muscle, and increase lactate clearance, and is thereby beneficial to reduced muscle fatigue after exercise.
\end{abstract}

Keywords: antioxidant capacity; exercise; lactate clearance; mangosteen; oxidative stress

\section{Introduction}

Exercise at moderate or high intensity results in the production of lactate in skeletal muscle and the subsequent elevation of its concentration in blood plasma. Lactate is derived from the glycolytic reduction of pyruvate, a reversible reaction that is catalyzed by lactate dehydrogenase (LDH). The relative amount of metabolism via $\mathrm{LDH}$ in the forward (pyruvate $+\mathrm{NADH}+\mathrm{H}^{+} \rightarrow$ lactate + $\mathrm{NAD}^{+}$) and reverse directions (lactate $+\mathrm{NAD}^{+} \rightarrow$ pyruvate $+\mathrm{NADH}+\mathrm{H}^{+}$) determines to some extent whether pyruvate or lactate will be oxidized within cells. Lactate accumulation is associated with the hypoxia and oxygen debt effect following exercise. Thus, lactate plays a major role in muscle fatigue and acidosis-induced tissue damage [1,2]. However, lactate is also an important intermediary product in many metabolic processes, acting as a mobile fuel for aerobic metabolism. Lactate generation is influenced to a great extent by flux through glycolysis, the redox state, and metabolism via the LDH pathway $[1,3,4]$. The liver exhibits a higher net lactate clearance than any other organ, estimated at $70 \%$ of the whole body clearance [5]. The onset of muscle fatigue after exercise has also been associated with oxidative stress. Previous studies have reported significantly increased malonaldehyde (MDA) levels in muscle and the liver after exercise. Exhaustive exercise can generate reactive oxygen species (ROS), 
leading to significant muscle damage and inflammatory stress [6-8]. The major antioxidant system in vivo is comprised of superoxide dismutase (SOD) that rapidly dismutates the superoxide anion $\mathrm{O}_{2}{ }^{-}$ to $\mathrm{H}_{2} \mathrm{O}_{2}$ and is then eliminated by glutathione peroxidase (GPx) and catalase (CAT) into water [9].

Mangosteen (Garcinia Mangostana) is an evergreen tree, originating from the Sun hin Islands and Moluccas region of Malaysia. The pericarp of the mangosteen fruit and the yellow gum in aril are rich in active secondary metabolites, namely xanthones. The major compounds of the mangosteen xanthones comprise $\alpha$-mangostin and $\gamma$-mangostin, which have shown anti-inflammatory $[10,11]$ and antioxidant $[12,13]$ properties in various studies. Given the importance of oxidative stress, inflammation, and muscle damage associated with high-intensity exercise, we would like to assess the effect of oral supplementation with mangosteen xanthones capable of diminishing oxidative stress generation and muscle damage. The purpose of this study was to examine the effect of mangosteen concentrate drink $(\mathrm{MCD})$ consumption on lactate metabolism and antioxidant capacity in rats after exercise by treadmill running.

\section{Materials and Methods}

\subsection{Animals}

Forty male Sprague Dawley (SD) rats aged 6 weeks and weighing $250 \pm 20$ g were purchased from the BioLASCO Taiwan Co., Ltd. (Taipei, Taiwan). The rats were individually housed in polycarbonate cages with stainless steel lids in an air-conditioned room $\left(23 \pm 2{ }^{\circ} \mathrm{C}, 65 \% \pm 5 \% \mathrm{RH}\right)$ with a $12 \mathrm{~h}$ light-dark cycle and free access to a standard chow diet (Labdiet ${ }^{\circledR} 5001$, Land O'Lake Inc., St. Louis, MI, USA) and water for one week before the experiment. All the animal experimental procedures were approved by the Institutional Animal Care and Use Committee of Taipei Medical University, Taipei, Taiwan.

\subsection{Diets and Experimental Groups}

Forty rats were divided into five groups, including non-treatment (N), control (C), 1× dose (M1), $5 \times$ dose (M5), and 10 $\times$ dose (M10) groups; there were eight rats in each group. The $\mathrm{N}$ group had a non-exercise test and MCD supplementation; the $C$ group only had exercise tests; the other groups all had exercise tests and MCD supplementation. All the groups were fed with a $28 \mathrm{~g}$ standard chow diet every day and additional appropriate dosages by p.o. between 1 and 5 p.m. (M1, 0.9 mL/day; M5, $4.5 \mathrm{~mL} /$ day; M10, $9 \mathrm{~mL} /$ day) for 6 weeks. The mangosteen concentrate drink was purchased from the LordDuke Biotechnology Co., Ltd. (Taipei, Taiwan). In brief, the MCD was processed by blending whole mangosteen fruit including pericarps, resulting in a red-brown drink. The density of the MCD was $1.1 \mathrm{~g} / \mathrm{mL}$ and it contained (per gram) 7 kilocalories, $6.36 \mathrm{mg}$ protein, $174.5 \mathrm{mg}$ carbohydrate, $8.2 \mathrm{mg}$ dietary fiber, and $1.44 \mathrm{mg}$ alpha-mangostin. Baseline fasting blood samples were collected from the tail vein of all rats after anesthetization. Additional fasting blood samples were collected after 3 and 6 weeks of MCD supplementation. The tested rats fasted for $12 \mathrm{~h}$ before the blood sample collection. Furthermore, the blood samples of the rats, except the $\mathrm{N}$ group, were collected immediately after a $30 \mathrm{~min}$ treadmill running exercise and after a $30 \mathrm{~min}$ post-running rest at week 2 and week 4 . At the end of experiment, all the rats (except the $\mathrm{N}$ group) were subjected to an exhaustive running test to determine the exhaustion time, and then blood samples of all the groups were drawn by exsanguination from the abdominal aorta and the liver and gastrocnemius muscle were collected. The blood lactate levels were measured immediately after the blood collection and all the collected samples were frozen at $-70{ }^{\circ} \mathrm{C}$ for other analyses.

\subsection{Treadmill Running Exercise Test}

Treadmill running exercise was performed using a motor-driven treadmill comprising a $60 \mathrm{~W}$ electric motor, $120 \times 60 \mathrm{~cm}$ 6-ways running surface, $0-30 \mathrm{~m} /$ minute speed control, and $0^{\circ}-30^{\circ}$ incline angle control. A shock grid at the rear end of the motor-driven treadmill supplied a mild electric stimulation to the feet $(450 \mathrm{~V}, 10-15 \mathrm{~mA})$ when the rats refused to run at the set treadmill rate. Briefly, 
the protocols of the habituation and the exercise tests were modified from those of Soya et al. [14]. The rats (except the $\mathrm{N}$ group) were initially acclimated to run for 2 days with a graded increase in velocity (from 10 to $25 \mathrm{~m} / \mathrm{min}$ ) within $15 \mathrm{~min}$ on the treadmill prior to the $30 \mathrm{~min}$ running and exhaustion tests. In the running tests, the treadmill speed was set from 5 to $20 \mathrm{~m} / \mathrm{min}$ within the initial twenty mins and then set up at $20 \mathrm{~m} / \mathrm{min}\left(5^{\circ}\right.$ upward tilt) for three $\mathrm{min}, 20 \mathrm{~m} / \mathrm{min}$ ( $10^{\circ}$ upward tilt) for three $\mathrm{min}$, and finally $25 \mathrm{~m} / \mathrm{min}\left(10^{\circ}\right.$ upward tilt) until $30 \mathrm{~min}$ or exhaustion.

\subsection{Determination of Exhaustion Time}

After 6 weeks of MCD treatment, the exhaustion time of the test groups was determined by counting the running time until exhaustion. The rats were considered exhausted when they still refused to run despite receiving stimulation on their feet. The time to exhaustion was defined as the time between the commencement of running and the failure of rats to keep up with the speed of the treadmill.

\subsection{Analysis of Plasma Glucose, Cholesterol, Triglycerides, and Lactate}

Appropriate commercial kits (Randox Laboratories, Crumlin, UK) were used to determine the concentrations of glucose, cholesterol, triglycerides, and lactate.

\subsection{Analysis of Antioxidant Enzymes Activities and Malondialdehyde (MDA) Levels}

The gastrocnemius and liver samples were homogenized in a $0.1 \mathrm{M}$ potassium phosphate buffer (pH 7.4) with a homogenizer (Qiagen ${ }^{\circledR}$ Tissuelyser II, Hilden, Germany). The supernatants were collected after being centrifuged at $10,000 \times g\left(10 \mathrm{~min} ., 4^{\circ} \mathrm{C}\right)$. The protein contents of tissue samples were measured using a Pierce ${ }^{\circledR}$ BCA protein assay kit (Thermo Fisher Scientific Inc., Waltham, MA, USA) prior to analyzing the antioxidant enzyme activities and MDA levels. The activities of SOD, GPx, and CAT were analyzed using commercial kits (RANDOX Laboratories Ltd., UK). The MDA level was evaluated using a thiobarbituric acid reactive substances assay kit (Cayman Chemical, Ann Arbor, MI, USA). The TBARS data were expressed as nanomoles of MDA per milliliter (in plasma) or per milligram of protein (in tissues).

\subsection{Statistical Analysis}

A statistical analysis of the data was performed using the SPSS statistical software (version 19.0). The results were expressed as the mean \pm SD. The differences between the parameters were analyzed by a one way analysis of variance followed by Duncan's multiple range test for a post hoc analysis. The differences were considered significant at a $p<0.05$.

\section{Results}

\subsection{Body Weight and Fasting Plasma Glucose, Lipids, and MDA Levels}

As shown in Supplementary Table S1, no significant changes were observed in the body weights between all the treatment groups in the study. Further, Supplementary Table S2 shows there were no significant differences in the diet consumption amounts between the various treatment groups during the experimental period. Before the MCD administration, the fasting plasma glucose and lipid levels of the rats were not significantly different between all the groups (Table 1). After 3 weeks of MCD consumption, the fasting plasma triglycerides concentrations of the rats in the C, M1, M5, and M10 groups were $29.5 \%, 28.7 \%, 40.9 \%$, and 38.5\%, respectively-significantly lower than levels of the N group (Table 1). Furthermore, the triglycerides concentrations of the M5 and M10 groups were significantly decreased by $16.1 \%$ and $12.8 \%$, respectively, compared with the C group. The total cholesterol concentrations of the M10 group were significantly decreased by $12.8 \%$ compared with the $\mathrm{N}$ group and significantly decreased by $6.3 \%$ compared with the $\mathrm{C}$ group. 
Table 1. Body weight and fasting plasma biochemical levels of the rats during the treatment period ${ }^{1,2}$.

\begin{tabular}{|c|c|c|c|c|c|}
\hline & $\mathbf{N}$ & $\mathrm{C}$ & M1 & M5 & M10 \\
\hline \multicolumn{6}{|l|}{ Initial } \\
\hline Weight (g) & $318.3 \pm 12.3$ & $313.4 \pm 8.2$ & $317.6 \pm 14.6$ & $312.0 \pm 10.2$ & $318.4 \pm 9.1$ \\
\hline Glucose (mg/dL) & $136.6 \pm 16.3$ & $139.5 \pm 14.0$ & $141.0 \pm 7.4$ & $130.8 \pm 6.8$ & $134.5 \pm 13.4$ \\
\hline Triglycerides (mg/dL) & $56.22 \pm 5.39$ & $58.40 \pm 6.80$ & $60.50 \pm 5.45$ & $57.92 \pm 3.61$ & $55.20 \pm 5.26$ \\
\hline Cholesterol (mg/dL) & $65.34 \pm 8.67$ & $70.20 \pm 7.15$ & $71.40 \pm 5.35$ & $65.00 \pm 3.28$ & $65.23 \pm 4.50$ \\
\hline MDA (nmole/mL) & $0.52 \pm 0.03$ & $0.52 \pm 0.02$ & $0.53 \pm 0.03$ & $0.52 \pm 0.02$ & $0.53 \pm 0.02$ \\
\hline \multicolumn{6}{|l|}{ After 3 weeks feeding } \\
\hline Weight (g) & $414.0 \pm 14.7$ & $417.3 \pm 21.9$ & $418.2 \pm 25.8$ & $425.1 \pm 12.1$ & $428.4 \pm 20.7$ \\
\hline Glucose $(\mathrm{mg} / \mathrm{dL})$ & $154.1 \pm 12.8$ & $142.1 \pm 12.1$ & $150.8 \pm 13.7$ & $145.8 \pm 12.0$ & $139.2 \pm 15.1$ \\
\hline Triglycerides (mg/dL) & $82.02 \pm 7.93^{c}$ & $57.83 \pm 9.68^{b}$ & $58.45 \pm 3.87^{b}$ & $48.50 \pm 8.65^{\mathrm{a}}$ & $50.41 \pm 9.75^{a b}$ \\
\hline Cholesterol (mg/dL) & $64.71 \pm 5.37^{b}$ & $60.21 \pm 3.24 \mathrm{ab}$ & $63.46 \pm 4.37^{b}$ & $64.50 \pm 3.89^{b}$ & $56.40 \pm 6.12^{\mathrm{a}}$ \\
\hline MDA (nmole/mL) & $0.57 \pm 0.04$ & $0.55 \pm 0.02$ & $0.55 \pm 0.03$ & $0.54 \pm 0.05$ & $0.54 \pm 0.03$ \\
\hline \multicolumn{6}{|l|}{ After 6 weeks feeding } \\
\hline Weight (g) & $473.1 \pm 23.5$ & $450.3 \pm 20.0$ & $467.5 \pm 29.8$ & $470.3 \pm 15.9$ & $464.9 \pm 22.6$ \\
\hline Glucose $(\mathrm{mg} / \mathrm{dL})$ & $158.0 \pm 10.0^{b}$ & $136.8 \pm 7.1^{\mathrm{a}}$ & $140.8 \pm 15.9^{\mathrm{a}}$ & $144.4 \pm 12.2^{\mathrm{a}}$ & $135.1 \pm 9.7^{\mathrm{a}}$ \\
\hline Triglycerides (mg/dL) & $87.60 \pm 8.91^{c}$ & $58.13 \pm 6.10^{b}$ & $57.60 \pm 3.60^{b}$ & $52.87 \pm 2.42^{\mathrm{ab}}$ & $48.12 \pm 3.30^{\mathrm{a}}$ \\
\hline Cholesterol (mg/dL) & $63.84 \pm 5.91^{c}$ & $55.67 \pm 8.38^{b}$ & $55.76 \pm 8.30^{b}$ & $51.92 \pm 7.48^{a b}$ & $45.03 \pm 3.18^{a}$ \\
\hline MDA (nmole/mL) & $0.65 \pm 0.03^{c}$ & $0.60 \pm 0.02^{b}$ & $0.57 \pm 0.03^{a b}$ & $0.54 \pm 0.04^{\mathrm{a}}$ & $0.53 \pm 0.05^{a}$ \\
\hline
\end{tabular}

${ }^{1}$ Values are means $\pm \mathrm{SD}, \mathrm{n}=8 . \mathrm{N}$, non-treatment; C, control; M1 $(0.9 \mathrm{~mL} /$ day mangosteen concentrate drink (MCD)); M5 (4.5 mL/day MCD); and M10 (9 mL/day MCD). ${ }^{2}$ Values in the same row with different letter superscripts indicate a significant change between the groups $(p<0.05)$; if without superscripts, they indicate no significant difference.

After 6 weeks of treatment, the fasting plasma glucose concentrations in the C, M1, M5, and M10 groups $(13.4 \%, 10.9 \%, 8.6 \%$, and $14.5 \%$, respectively) were significantly lower than levels of the $\mathrm{N}$ group (Table 1). The total cholesterol (TC) concentrations were significantly decreased by $12.8 \%, 12.7 \%, 18.7 \%$, and $29.5 \%$, respectively. The triglycerides (TG) concentrations were significantly decreased by $33.6 \%$, $34.2 \%, 39.6 \%$, and $45.1 \%$, respectively. Moreover, the TG and TC concentrations of the M10 group were significantly decreased by $17.2 \%$ and $19.1 \%$, respectively, compared with those of the C group. These results reveal that short periodic running exercise treatment and daily MCD administration can improve glucose and lipid metabolism in vivo.

\subsection{Plasma Lactate Levels of the Rats in the 30 Min Running Test}

After 2 weeks of MCD supplementation, the plasma lactate levels of the M1, M5, and M10 groups whether before running, after running, or after rest were not significantly different when compared with the levels in the $C$ group (Table 2). However, after 4 weeks of treatment, the plasma lactate levels of the rats in the M5 and M10 groups after a post-running rest were significantly decreased by $19.0 \%$ and $10.9 \%$, respectively. During the post-running rest, the reduction in lactate levels in the M5 and M10 groups was significantly elevated by $12.5 \%$ and $25.5 \%$, respectively, compared with the C group. These results reveal that MCD consumption promoted the elimination of plasma lactate during rest after exercise.

Table 2. Plasma lactate levels of the rats in the 30 min running period after mangosteen supplementation ${ }^{1,2}$.

\begin{tabular}{lcccc}
\hline & C & M1 & M5 & M10 \\
\hline Lactate (mg/dL) & \multicolumn{4}{c}{ After 2 weeks feeding } \\
Before running (a) & $16.19 \pm 2.19$ & $15.23 \pm 3.50$ & $16.40 \pm 3.31$ & $17.13 \pm 1.98$ \\
After 30 min running (b) & $27.41 \pm 2.16$ & $25.88 \pm 3.25$ & $26.28 \pm 2.80$ & $27.20 \pm 2.05$ \\
Lactate increase during running (b-a) & $11.22 \pm 3.58$ & $10.66 \pm 1.48$ & $9.88 \pm 1.44$ & $10.07 \pm 1.37$ \\
After resting (c) & $18.71 \pm 2.27$ & $15.72 \pm 3.39$ & $16.53 \pm 2.61$ & $16.36 \pm 1.68$ \\
Lactate decrease during resting (c-b) & $9.07 \pm 0.59$ & $10.16 \pm 0.82$ & $9.92 \pm 0.78$ & $10.84 \pm 1.41$ \\
\hline
\end{tabular}


Table 2. Cont.

\begin{tabular}{lcccc}
\hline & C & M1 & M5 & M10 \\
\hline Lactate (mg/dL) & \multicolumn{4}{c}{ After 4 weeks feeding } \\
Before running (a) & $15.40 \pm 3.56$ & $15.08 \pm 2.42$ & $14.73 \pm 2.58$ & $14.66 \pm 1.64$ \\
After 30 min running (b) & $25.13 \pm 2.81$ & $24.99 \pm 2.93$ & $24.65 \pm 3.11$ & $24.53 \pm 2.62$ \\
Lactate increase during running (b-a) & $9.73 \pm 1.13$ & $9.91 \pm 1.01$ & $9.92 \pm 1.28$ & $9.97 \pm 1.16$ \\
After resting (c) & $15.54 \pm 2.03^{\mathrm{b}}$ & $14.67 \pm 1.74^{\mathrm{ab}}$ & $13.85 \pm 1.15^{\mathrm{a}}$ & $12.58 \pm 1.94^{\mathrm{a}}$ \\
Lactate decrease during resting (c-b) & $9.60 \pm 0.90^{\mathrm{a}}$ & $10.32 \pm 1.59^{\mathrm{ab}}$ & $10.80 \pm 2.18^{\mathrm{b}}$ & $12.05 \pm 1.08^{\mathrm{b}}$ \\
\hline
\end{tabular}

${ }^{1}$ Values are means \pm SD, $\mathrm{n}=8$. C, control; M1 (0.9 mL/day MCD); M5 (4.5 mL/day MCD); and M10 (9 mL/day MCD). ${ }^{2}$ Values in the same row with the different letter superscripts indicate a significant change between the groups $(p<0.05)$; if without superscripts, they indicate no significant difference.

\subsection{Running Time and Lactate Levels of the Rats in the Exhaustive Running Test}

After 6 weeks of MCD supplementation, the running times of the testing groups in exhaustive test were not significantly different. Nevertheless, the running time of the M10 group was increased by 9.5\% compared with the values of the C group (Table 3). The plasma lactate levels of the M1, M5, and M10 groups before/after running and after resting were not significantly different when compared with the $\mathrm{C}$ group. However, the lactate reduction in the M10 group during resting was significantly increased by $27.0 \%$ compared with the C group (Table 3 ).

Table 3. Running time and plasma lactate levels of the rats in the exhaustive running period after 6 weeks mangosteen treatment ${ }^{1,2}$.

\begin{tabular}{lcccc}
\hline & C & M1 & M5 & M10 \\
\hline Running time (seconds) & $2331 \pm 329$ & $2361 \pm 190$ & $2354 \pm 159$ & $2585 \pm 130$ \\
Lactate (mg/dL) & & & & \\
Before running (a) & $14.36 \pm 2.58$ & $14.00 \pm 2.49$ & $15.92 \pm 3.62$ & $16.32 \pm 1.57$ \\
After 30 min running (b) & $138.51 \pm 41.14$ & $152.39 \pm 17.47$ & $133.65 \pm 26.65$ & $170.61 \pm 23.60$ \\
Lactate increase during running (b-a) & $124.16 \pm 43.20$ & $138.39 \pm 15.79$ & $117.72 \pm 28.29$ & $154.29 \pm 23.52$ \\
After resting (c) & $45.69 \pm 10.15$ & $53.71 \pm 17.33$ & $37.74 \pm 10.70$ & $43.54 \pm 5.97$ \\
Lactate decrease during resting (c-b) & $92.82 \pm 33.47^{\mathrm{a}}$ & $98.69 \pm 12.66^{\mathrm{a}}$ & $95.91 \pm 27.79^{\mathrm{a}}$ & $127.07 \pm 25.30^{\mathrm{b}}$ \\
\hline
\end{tabular}

${ }^{1}$ Values are means $\pm \mathrm{SD}, \mathrm{n}=8$. C, control; M1 (0.9 mL/day MCD); M5 (4.5 mL/day MCD); and M10 (9 mL/day $\mathrm{MCD}) .{ }^{2}$ Values in the same row with different letter superscripts indicate a significant change between the groups $(p<0.05)$; if without superscripts, they indicate no significant difference.

\subsection{Hepatic and Muscular MDA Levels and Antioxidant Enzymes Activities of the Rats after the Exhaustive Running Test}

The hepatic MDA levels of the rats in the M5 and M10 groups were significantly decreased by $17.3 \%$ and $15.4 \%$, respectively, compared with the $C$ group after the exhaustive test (Table 4). Moreover, the hepatic SOD activities of the rats in the M5 and M10 groups were significantly decreased by $16.8 \%$ and $19.5 \%$, respectively, compared with the C group; as well, the hepatic CAT activities decreased by $17.7 \%$ and $14.8 \%$. The muscular MDA levels of the rats in the C, M1, M5, and M10 groups were not significantly different. However, only the muscular MDA level of the $\mathrm{C}$ group was increased by $19.6 \%$ compared with $\mathrm{N}$ group, although this was not significant (Table 4). Furthermore, the muscular SOD activity of the rats in the M10 group was significantly decreased by $17.3 \%$ compared with the C group, but the hepatic GPx activities of the M5 and M10 groups were significantly increased by $16.8 \%$ and $19.5 \%$, respectively. The results of the $\mathrm{N}$ and $\mathrm{C}$ groups reveal that exhaustive running could increase the hepatic and muscular MDA levels, although not significantly, and significantly increase the antioxidant enzymatic activities. Moreover, the consumption of MCD could eliminate the hepatic and muscular MDA levels. 
Table 4. Antioxidant enzyme activities and malonaldehyde (MDA) levels of the liver and muscles in rats after the exhaustive running test ${ }^{1-3}$.

\begin{tabular}{|c|c|c|c|c|c|}
\hline & $\mathbf{N}$ & $C$ & M1 & M5 & M10 \\
\hline $\begin{array}{l}\text { Hepatic MDA } \\
\text { (nmole/mg protein) }\end{array}$ & $1.26 \pm 0.09^{b}$ & $1.33 \pm 0.11^{b}$ & $1.30 \pm 0.15^{b}$ & $1.06 \pm 0.05^{\mathrm{a}}$ & $1.11 \pm 0.09^{a}$ \\
\hline $\begin{array}{l}\text { Hepatic SOD } \\
\text { (unit/mg protein) }\end{array}$ & $142.6 \pm 19.7^{b}$ & $148.2 \pm 16.9^{b}$ & $149.6 \pm 9.9^{b}$ & $123.3 \pm 11.0^{\mathrm{a}}$ & $119.3 \pm 13.6^{a}$ \\
\hline $\begin{array}{l}\text { Hepatic GPx } \\
\text { (unit/mg protein) }\end{array}$ & $163.5 \pm 7.6^{\mathrm{a}}$ & $178.2 \pm 9.9^{b}$ & $177.4 \pm 10.7^{b}$ & $182.3 \pm 19.9^{b}$ & $182.9 \pm 11.0^{b}$ \\
\hline $\begin{array}{l}\text { Hepatic CAT } \\
\text { (mmole/min/mg protein) }\end{array}$ & $48.5 \pm 16.0^{\mathrm{a}}$ & $126.8 \pm 7.4^{\mathrm{c}}$ & $115.5 \pm 15.9^{b c}$ & $104.4 \pm 8.8^{b}$ & $108.0 \pm 11.2^{b}$ \\
\hline $\begin{array}{l}\text { Muscular MDA } \\
\text { (nmole/mg protein) }\end{array}$ & $0.46 \pm 0.13$ & $0.55 \pm 0.10$ & $0.45 \pm 0.06$ & $0.45 \pm 0.09$ & $0.45 \pm 0.09$ \\
\hline $\begin{array}{l}\text { Muscular SOD } \\
\text { (unit/mg protein) }\end{array}$ & $87.90 \pm 7.00^{a}$ & $96.98 \pm 11.58^{b}$ & $96.30 \pm 5.82^{b}$ & $86.99 \pm 6.68 \mathrm{ab}$ & $80.20 \pm 6.87^{a}$ \\
\hline $\begin{array}{l}\text { Muscular GPx } \\
\text { (unit/mg protein) }\end{array}$ & $7.24 \pm 1.49^{a}$ & $7.41 \pm 1.08^{a}$ & $7.52 \pm 1.20^{a}$ & $9.08 \pm 1.72^{b}$ & $11.66 \pm 1.85^{c}$ \\
\hline $\begin{array}{l}\text { Muscular CAT } \\
\text { (mmole/min/mg protein) }\end{array}$ & $3.04 \pm 0.55^{\mathrm{a}}$ & $3.79 \pm 0.34^{b}$ & $4.37 \pm 0.97^{b}$ & $4.12 \pm 0.57^{b}$ & $5.11 \pm 0.64^{c}$ \\
\hline
\end{tabular}

${ }^{1}$ Values are means $\pm \mathrm{SD}, \mathrm{n}=8 .{ }^{2}$ Values in the same row with different letter superscripts indicate a significant change between the groups $(p<0.05)$; if without superscripts, they indicate no significant change. $\mathrm{N}$, non-treatment; C, control; M1 (0.9 mL/day MCD); M5 (4.5 mL/day MCD); and M10 (9 mL/day MCD). ${ }^{3}$ The rats in the C, M1, M5, and M10 groups were sacrificed after the exhaustive running test and $30 \mathrm{~min}$ post- running rest, but rats in the $\mathrm{N}$ group were sacrificed without running.

\section{Discussion}

\subsection{Effect of MCD Supplementation on Fasting Plasma Biochemical Parameters}

At the end of this study, the fasting plasma TG and TC of the M10 group were significantly decreased compared with the $\mathrm{C}$ and other MCD supplement groups. The results showed that $\mathrm{MCD}$ supplement could improve glucose and lipid metabolism in vivo. This is in agreement with findings of a previous human study that showed 8 weeks administration of capsules containing mangosteen fruit powder significantly decreased the total cholesterol and triglyceride levels [15]. In a previous in vitro study, $\alpha$-MG from the hulls of mangosteen was found to inhibit fatty acid synthase (FAS) [16]. Moreover, a previous study suggested that $\alpha$-MG exerts anti-obesity effects, ameliorates insulin resistance, and reduces TG and total cholesterol levels in high fat diet-induced obese mice by activating the hepatic AMPK, SirT1, and PPAR $\gamma$ expression, which has been found to increase the rates of fatty acid oxidation and repress lipogenesis [17]. In order to further elucidate the underlying effect of MCD on lactate clearance, we suggest that further studies include the hepatic concentration of TG and TC.

\subsection{Effect of MCD Supplementation on the Lactate Clearance of the Rats after Running Tests}

In this study, plasma lactate clearance was significantly increased in the MCD supplementation groups after running tests. The M10 group had longest running time and highest rate of lactate clearance compared with the other groups after the exhaustive exercise test. Previous studies showed that the production and removal of lactate in vivo occur via a reversible redox reaction catalyzed by $\mathrm{LDH}$, which is located in the cytoplasm $[18,19]$. The main source of lactate production in humans includes intracellular glucose $(65 \%)$ and alanine $(16 \%-20 \%)$, because glycolysis involves a series of steps by which glucose is metabolized into pyruvate in the cytoplasm and later converted to lactate. Under hypoxic conditions, pyruvate is reduced to lactate, whereas the reduced nicotinamide adenine dinucleotide (NADH) is oxidized to $\mathrm{NAD}^{+}$[20]. The lactate threshold has been defined as the work rate or oxygen uptake beyond which the blood lactate concentration begins to rise more rapidly [21]. In resting muscle and the post-absorptive state, blood lactate from skeletal muscle provides about $40 \%$ of lactic acid in the systemic circulation and the net lactate extraction by the liver is partly aimed at the production of endogenous glucose; however, some researches showed that in active 
muscles, either lactate release or extraction are comparable to the levels in muscles at rest [22,23]. The conversion of lactate into pyruvate via LDH catalytic oxidation is an important step towards eliminating accumulated lactate in the cytoplasm [24]. In addition, the production of endogenous glucose through gluconeogenesis can also contribute to lactate clearance. Some studies have indicated that hepatic lactate uptake and gluconeogenesis are increased during the exercise period [24-26]. Endurance training can reduce lactate production in exercise muscle and release to blood, because exercise may enhance the oxidation efficiency of the respiratory chain, hence reducing non-oxidative glycolysis and lactate formation [27-29].

\subsection{Effect of MCD Supplementation on Hepatic and Muscular Antioxidant Enzymes Activities and the MDA Levels of the Rats after Running Tests}

In the present study, the muscular MDA levels of the MCD consumption groups were decreased compared with the $\mathrm{C}$ group, although these were not significant after the exhaustive test. However, the hepatic MDA levels of the M5 and M10 groups declined markedly compared with the C group. In this study, it was found that exhaustive exercise caused increased muscular MDA levels but did not affect the hepatic MDA levels. Vasilaki et al. and Zheng et al. have represented that endurance and high-strength or exhaustive exercises cause muscle damage accompanied by oxidative stress and inflammation, leading to muscle fatigue and muscle soreness [30,31]. Previous studies also have reported increased MDA contents in the muscles and liver after prolonged or intense exercise. The variation between the hepatic MDA content of the rats after exercise between the present and previous studies may have arisen from elevated plasma glucose, triglycerides, and cholesterol levels of the rats in the $\mathrm{N}$ group in this study. It has been reported that hyperlipidemic or hyperglycemic rats have significantly higher hepatic MDA levels [32,33].

Hellsten et al. and Viña et al. found xanthine oxidase (XO)-derived ROS as a significant source of ROS after prolonged or intense exercise as well as mitochondria-derived ROS [34,35]. The xanthine oxidase $(\mathrm{XO})$ mediated the oxidation of hypoxanthine to xanthine; the further oxidation of xanthine to uric acid produces hydrogen peroxide consecutively eliminated by GPx and CAT through conversion into water. Previous studies reported that the inhibition of XO with allopurinol (a XO inhibitor) afforded protection against free radical production and tissue damage associated with exhaustive exercise in animals and humans $[35,36]$. The results in this study showed that the increased production of ROS during exhaustive exercise had to be eliminated by antioxidant enzymes in vivo; thus, the GPx and CAT activities of the exhaustive exercise groups were more increased than in the N group. Moreover, the results also revealed that MCD consumption could promote GPx and CAT activities, especially in muscle. This study demonstrated that MCD could improve the antioxidant capacity and lactate clearance in rats after exercise. However, the respiratory efficiency of the rats was not analyzed because of limitations of the measurement equipment. In addition, we propose further studies to determine the hepatic concentrations of xanthine compounds in relation to TG, TC, and lactate clearance in order to fully elucidate the underlying mechanism of MCD effects.

\section{Conclusions}

This is the first demonstration of the potential utility of mangosteen concentrate drink to alleviate muscle fatigue during exercise via reducing oxidative stress and increasing lactate clearance. As demonstrated in the proposed mechanistic model in Figure 1, MCD supplementation can increase GPx and CAT activities, alleviate oxidative stress in muscle, and increase lactate clearance; it is thereby beneficial in reducing muscle fatigue after exercise. 


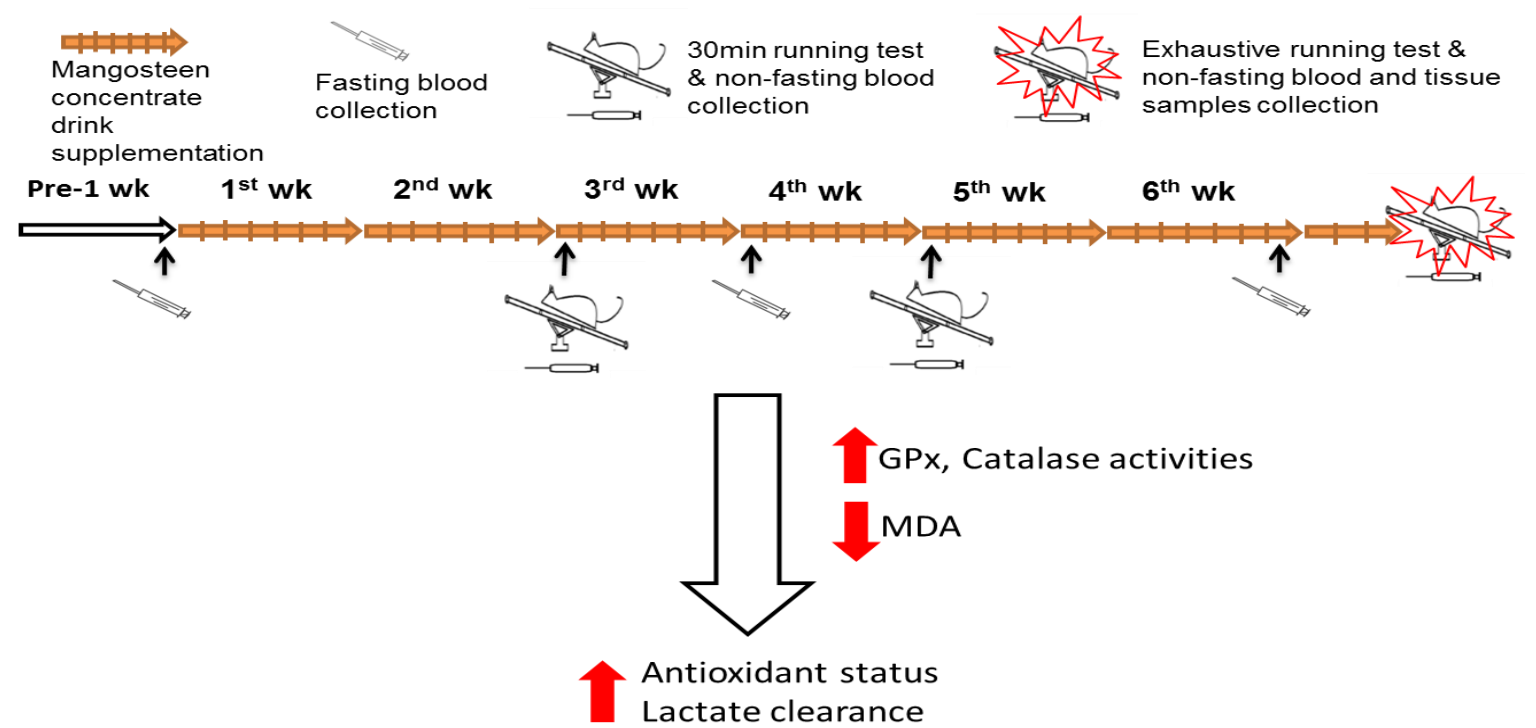

Figure 1. Experiment flow figure. The purpose of this study was to examine the effect of mangosteen concentrate drink (MCD) supplementation on the antioxidant capacity and lactate clearance in rats after running exercise. Forty rats were divided into 5 groups: N, non-treatment; $\mathrm{C}$, control; or supplemented with MCD, including M1, M5, and M10 (0.9, 4.5, and $9 \mathrm{~mL} /$ day) for 6 weeks. The rats were subjected to 30 min exhaustive running tests using a treadmill and sample collections. The results of this study demonstrated that MCD supplementation can increase glutathione peroxidase (GPx) and catalase (CAT) activities, alleviate oxidative stress in muscle, and increase lactate clearance; it is thereby beneficial in reducing muscle fatigue after exercise.

Supplementary Materials: The following are available online at http://www.mdpi.com/2072-6643/12/5/1447/s1, Table S1: title. Body weight (grams) of the rats during treatment period; Table S2. Diet consumptions (grams) of the rats per week during treatment period.

Author Contributions: C.-C.C. and R.-H.H. conceived the study, participated in its design, and helped to draft the manuscript. C.-C.C., C.-W.C., W.-T.L., and T.-N.L. carried out the animal feeding and exercise experiment. C.-C.C. and C.-W.C. were involved in the biochemical analysis and drafted the manuscript. E.O. helped to draft and improve the manuscript. All authors have read and agreed to the published version of the manuscript.

Funding: This research was funded by the National Science Council, Taiwan (grant number: NSC 102-2320-B-038032-MY2).

Acknowledgments: The authors thank the School of Nutrition and Health Sciences, Taipei Medical University, Taiwan, for providing the facilities to carry out this study. This study was supported by a grant from the National Science Council, Taiwan (Grant number: NSC 102-2320-B-038-032-MY2).

Conflicts of Interest: The authors declare no conflict of interest.

\section{References}

1. Gladden, L.B. Lactate metabolism: A new paradigm for the third millennium. J. Physiol. 2004, 558, 5-30. [CrossRef] [PubMed]

2. Robergs, R.A.; Ghiasvand, F.; Parker, D. Biochemistry of exercise-induced metabolic acidosis. Am. J. Physiol. Regul. Integr. Comp. Physiol. 2004, 287, R502-R516. [CrossRef] [PubMed]

3. McKenna, M.C.; Gruetter, R.; Sonnewald, U.; Waagepetersen, H.S.; Schousboe, A. Energy metabolism of the brain. In Basic Neurochemistry: Molecular, Cellular, and Medical Aspects; Siegel, G.J., Albers, R.W., Bradey, S.T., Price, D.P., Eds.; Elsevier Academic Press: New York, NY, USA, 2006.

4. Brooks, G.A. Cell-cell and intracellular lactate shuttles. J. Physiol. 2009, 587, 5591-5600. [CrossRef] [PubMed]

5. Van Hall, G. Lactate kinetics in human tissues at rest and during exercise. Acta Physiol. 2010, 199, 499-508. [CrossRef] [PubMed]

6. Pervaiz, N.; Hoffman-Goetz, L. Immune cell inflammatory cytokine responses differ between central and systemic compartments in response to acute exercise in mice. Exerc. Immunol. Rev. 2012, 18, 142-157. 
7. Huang, K.C.; Wu, W.T.; Yang, F.L.; Chiu, Y.H.; Peng, T.C.; Hsu, B.G.; Liao, K.W.; Lee, R.P. Effects of freshwater clam extract supplementation on time to exhaustion, muscle damage, pro/anti-inflammatory cytokines, and liver injury in rats after exhaustive exercise. Molecules 2013, 18, 3825-3838. [CrossRef]

8. Chang, Q.; Miao, X.; Ju, X.; Zhu, L.; Huang, C.; Huang, T.; Zuo, X.; Gao, C. Effects of pulse current on endurance exercise and its anti-fatigue properties in the hepatic tissue of trained rats. PLoS ONE 2013, 8, e75093. [CrossRef]

9. Marín, C.; Yubero-Serrano, E.M.; López-Miranda, J.; Pérez-Jiménez, F. Endothelial aging associated with oxidative stress can be modulated by a healthy mediterranean diet. Int. J. Mol. Sci. 2013, 14, 8869-8889. [CrossRef]

10. Bumrungpert, A.; Kalpravidh, R.W.; Chitchumroonchokchai, C.; Chuang, C.C.; West, T.; Kennedy, A.; McIntosh, M. Xanthones from mangosteen prevent lipopolysaccharide-mediated inflammation and insulin resistance in primary cultures of human adipocytes. J. Nutr. 2009, 139, 1185-1191. [CrossRef]

11. Jang, H.Y.; Kwon, O.K.; Oh, S.R.; Lee, H.K.; Ahn, K.S.; Chin, Y.W. Mangosteen xanthones mitigate ovalbumininduced airway inflammation in a mouse model of asthma. Food Chem. Toxicol. 2012, 50, 4042-4050. [CrossRef]

12. Williams, P.; Ongsakul, M.; Proudfoot, J.; Croft, K.; Beilin, L. Mangostin inhibits the oxidative modification of human low density lipoprotein. Free Radic. Res. 1995, 23, 175-184. [CrossRef] [PubMed]

13. Sukatta, U.; Takenaka, M.; Ono, H.; Okadome, H.; Sotome, I.; Nanayama, K.; Thanapase, W.; Isobe, S. Distribution of major xanthones in the pericarp, aril, and yellow gum of mangosteen (Garcinia mangostana linn.) fruit and their contribution to antioxidative activity. Biosci. Biotechnol. Biochem. 2013, 77, 984-987. [CrossRef] [PubMed]

14. Soya, H.; Mukai, A.; Deocaris, C.C.; Ohiwa, N.; Chang, H.; Nishijima, T.; Fujikawa, T.; Togashi, K.; Saito, T. Threshold-like pattern of neuronal activation in the hypothalamus during treadmill running: Establishment of a minimum running stress (MRS) rat model. Neurosci. Res. 2007, 58, 341-348. [CrossRef] [PubMed]

15. Stern, J.S.; Peerson, J.; Mishra, A.T.; Sadasiva Rao, M.V.; Rajeswari, K.P. Efficacy and tolerability of a novel herbal formulation for weight management. Obesity 2013, 21, 921-927. [CrossRef] [PubMed]

16. Quan, X.; Wang, Y.; Ma, X.; Liang, Y.; Tian, W.; Ma, Q.; Jiang, H.; Zhao, Y. $\alpha$-Mangostin induces apoptosis and suppresses differentiation of 3T3-L1 cells via inhibiting fatty acid synthase. PLoS ONE 2012, 7, e33376. [CrossRef]

17. Choi, Y.H.; Bae, J.K.; Chae, H.S.; Kim, Y.M.; Sreymom, Y.; Han, L.; Jang, H.Y.; Chin, Y.W. $\alpha$-Mangostin regulates hepatic steatosis and obesity through SirT1-AMPK and PPAR $\gamma$ pathways in high-hat diet-induced obese mice. J. Agric. Food Chem. 2015, 63, 8399-8406. [CrossRef]

18. Battezzati, A.; Caumo, A.; Martino, F.; Sereni, L.P.; Coppa, J.; Romito, R.; Ammatuna, M.; Regalia, E.; Matthews, D.E.; Mazzaferro, V.; et al. Nonhepatic glucose production in humans. Am. J. Physiol. Endocrinol. Metab. 2004, 286, E129-E135. [CrossRef]

19. Lemire, J.; Mailloux, R.J.; Appanna, V.D. Mitochondrial lactate dehydrogenase is involved in oxidative-energy metabolism in human astrocytoma cells (CCF-STTG1). PLoS ONE 2008, 3, e1550. [CrossRef]

20. Kreisberg, R.A. Lactate homeostasis and lactic acidosis. Ann. Intern. Med. 1980, 92, 227-237. [CrossRef]

21. Goodwin, M.L.; Harris, J.E.; Hernández, A.; Gladden, L.B. Blood lactate measurements and analysis during exercise: A guide for clinicians. J. Diabetes Sci. Technol. 2007, 1, 558-569. [CrossRef]

22. Jorfeldt, L. Metabolism of L (+)-lactate in human skeletal muscle during exercise. Acta Physiol. Scand. Suppl. 1970, 338, 1-67. [PubMed]

23. Stanley, W.C.; Gertz, E.W.; Wisneski, J.A.; Neese, R.A.; Morris, D.L.; Brooks, G.A. Lactate extraction during net lactate release in legs of humans during exercise. J. Appl. Physiol. 1986, 60, 1116-1120. [CrossRef] [PubMed]

24. Consoli, A.; Nurjhan, N.; Reilly, J.J.; Jr Bier, D.M.; Gerich, J.E. Contribution of liver and skeletal muscle to alanine and lactate metabolismin humans. Am. J. Physiol. 1990, 259, E677-E684. [PubMed]

25. Perriello, G.; Jorde, R.; Nurjhan, N.; Stumvoll, M.; Dailey, G.; Jenssen, T.; Bier, D.M.; Gerich, J.E. Estimation of glucose-alanine-lactate-glutamine cycles in postabsorptive humans: Role of skeletal muscle. Am. J. Physiol. 1995, 269, E443-E450. [CrossRef]

26. Ahlborg, G.; Felig, P.; Hagenfeldt, L.; Hendler, R.; Wahren, J. Substrate turnover during prolonged exercise in man. Splanchnic and leg metabolism of glucose, free fatty acids, and amino acids. J. Clin. Investig. 1974, 53, 1080-1090. [CrossRef]

27. Nielsen, H.B.; Clemmesen, J.O.; Skak, C.; Ott, P.; Secher, N.H. Attenuated hepatosplanchnic uptake of lactate during intense exercise in humans. J. Appl. Physiol. 2002, 92, 1677-1683. [CrossRef] 
28. Bergman, B.C.; Wolfel, E.E.; Butterfield, G.E.; Lopaschuk, G.D.; Casazza, G.A.; Horning, M.A.; Brooks, G.A. Active muscle and whole body lactate kinetics after endurance training in men. J. Appl. Physiol. 1999, 87, 1684-1696. [CrossRef]

29. Messonnier, L.A.; Emhoff, C.A.; Fattor, J.A.; Horning, M.A.; Carlson, T.J.; Brooks, G.A. Lactate kinetics at the lactate threshold in trained and untrained men. J. Appl. Physiol. 2013, 114, 1593-1602. [CrossRef]

30. Vasilaki, A.; Mansouri, A.; Van Remmen, H.; Van der Meulen, J.H.; Larkin, L.; Richardson, A.G.; McArdle, A.; Faulkner, J.A.; Jackson, M.J. Free radical generation by skeletal muscle of adult and old mice: Effect of contractile activity. Aging Cell 2006, 5, 109-117. [CrossRef]

31. Zheng, X.; Long, W.; Liu, G.; Zhang, X.; Yang, X. Effect of seabuckthorn (Hippophae rhamnoides ssp. sinensis) leaf extract on the swimming endurance and exhaustive exercise-induced oxidative stress of rats. J. Sci. Food. Agric. 2012, 92, 736-742. [CrossRef]

32. Küçükgergin, C.; Aydin, A.F.; Ozdemirler-Erata, G.; Mehmetçik, G.; Koçak-Toker, N.; Uysal, M. Effect of artichoke leaf extract on hepatic and cardiac oxidative stress in rats fed on high cholesterol diet. Biol. Trace Elem. Res. 2010, 135, 264-274. [CrossRef] [PubMed]

33. Li, D.; Peng, C.; Xie, X.; Mao, Y.; Li, M.; Cao, Z.; Fan, D. Antidiabetic effect of flavonoids from Malus toringoides (Rehd.) Hughes leaves in diabetic mice and rats. J. Ethnopharmacol. 2014, 153, 561-567. [CrossRef] [PubMed]

34. Hellsten, Y.; Frandsen, U.; Ortehenblad, N.; Sjodin, B.; Richter, E.A. Xanthine xidase in human skeletal muscle following eccentric exercise: A role in inflammation. J. Physiol. Lond. 1997, 498, 239-248. [CrossRef] [PubMed]

35. Viña, J.; Gimeno, A.; Sastre, J.; Desco, C.; Asensi, M.; Pallardó, F.V.; Cuesta, A.; Ferrero, J.A.; Terada, L.S.; Repine, J.E. Mechanism of free radical production in exhaustive exercise in humans and rats; role of xanthine oxidase and protection by allopurinol. IUBMB Life 2000, 49, 539-544. [PubMed]

36. Gomez-Cabrera, M.C.; Pallardo, F.V.; Sastre, J.; Viña, J.; Garcia-del-Moral, L. Allopurinol and markers of muscle damage among participants in the Tour de France. JAMA 2003, 289, 2503-2504. [CrossRef]

(C) 2020 by the authors. Licensee MDPI, Basel, Switzerland. This article is an open access article distributed under the terms and conditions of the Creative Commons Attribution (CC BY) license (http://creativecommons.org/licenses/by/4.0/). 